\title{
A convergência de referências na Promoção da Saúde
}

\section{The convergence of references in Health Promotion}

\author{
Willer Baumgarten Marcondes \\ Cientista Social, Doutorando da Ensp/Fiocruz e bolsista do CNPq. \\ E-mail: willerbm®ensp.fiocruz.br
}

\section{Resumo}

A constituição de um campo para a saúde pública de conhecimentos e práticas de promoção da saúde pode ser entendido pelo acúmulo histórico de contribuições da saúde comunitária, da medicina preventiva e da epidemiologia social, entre outros, que colaboraram para a conformação de uma abordagem da saúde de forma ampliada. Nesta confluência de referenciais variados, abordo neste artigo uma proposta de síntese entre algumas das principais questões que, radicalmente interligadas, conformariam os contornos da promoção da saúde. Postulo, desta forma, que o interesse na promoção da saúde seja justamente a construção desta interface entre a incorporação de boas práticas e questões para a saúde pública, fazendo, ao mesmo tempo, proposições articuladas e coerentes com o nosso momento histórico, marcado por um modelo neoliberal de globalização e pela hegemonia das tecnologias biomédicas. Este artigo está apoiado em três questões que considero fundamentais para abordar a promoção da saúde: as limitações do modelo biomédico, a ampliação do conceito de saúde e a diferença entre prevenção e promoção. Para tanto, recorro aos principais documentos históricos de referência à promoção da saúde para problematizar o que estamos discutindo como qualidade de vida, além das críticas ao "modismo" neoliberal que justificariam ideologicamente a retração do Estado e a culpabilização da população. Um caminho apontado a partir destas considerações é o de que a participação social na saúde pode oferecer um potencial para enfrentar os desafios e adequar o campo da promoção da saúde ao nosso contexto latino-americano.

Palavras-chave: Promoção da Saúde; Saúde Pública; Participação social. 
Abstract

The field of health promotion in public health has been formed by historical contributions of community health, preventive medicine and social epidemiology. In this article the author proposes a synthesis of the main issues that are integrated and conform Health Promotion. In our view, the challenge of Health Promotion is this interface between good practices in public health and the historical context, marked by a globalization and hegemony of biomedical practices. This article deals with three main issues for Health Promotion: limitations of the biomedical model, enlargement of health concept and the difference between prevention and promotion. Based on documents, the author points out the importance of community participation for Health promotion in Latin America. Key Words: Health Promotion, Public Health, Community Participation

\section{Introdução}

No percurso deste artigo destaco três questões que articulam idéias e referenciais que considero privilegiados para a abordagem da promoção da saúde. A primeira delas, certamente, volta-se para as limitações do modelo biomédico e para sua ênfase na clínica de orientação curativa para dar conta da saúde, sendo esta, por outro lado, entendida em um conceito ampliado e dotado da dimensão de processo dinâmico e em permanente mudança.

A segunda grande questão aqui apontada para a promoção da saúde desdobra a compreensão da saúde, anteriormente citada, para além da prática clínica e incorpora as condições de vida, geradas pelas relações sociais, como importante elemento do processo saúde-doença. Nele, partimos do reconhecimento de que o adoecimento e a vida saudável não dependem unicamente de aspectos físicos ou genéticos, mas são, também, e importantemente, influenciados pelas relações sociais que engendram formas de acesso à alimentação, educação, trabalho, renda, lazer, paz e ambientes saudáveis, entre outros aspectos fundamentais para a saúde e a qualidade de vida.

0 terceiro ponto a ser destacado enfatiza que, apesar de a crítica à insuficiência da perspectiva curativa existir em outras estratégias além da de promoção da saúde, esta, em especial, tem estabelecido uma importante diferença entre prevenir doenças e promover saúde, a despeito de a prevenção e a promoção terem em comum a ênfase no cuidado e não na cura. Nesse sentido, torna-se relevante qualificar tal diferença entre prevenção e promoção no que se refere aos paradigmas que os embasam (aqui entendidos como modelos conceituais), de forma a ressaltar suas respectivas contribuições para a saúde.

Com o apoio dos documentos históricos de referência à promoção da saúde abordo de modo mais detalhado a seguir estes três grupos de questões na convergência de campos da saúde pública.

\section{As Limitações do Modelo Biomédico}

Nos termos da Carta de Ottawa (Brasil/MS, 2001), documento fundador da promoção da saúde contemporânea, a limitação do modelo biomédico apontada é identificada de forma peremptória no "setor sanitá- 
rio”, o qual é descrito como necessário, porém insuficiente, para dar conta da saúde numa estratégia de promoção:

"O setor sanitário não pode, por si mesmo, proporcionar as condições prévias nem assegurar as perspectivas favoráveis para a saúde, além do que, a promoção da saúde exige a ação coordenada de todos os implicados: os governos, os setores sanitários e outros setores sociais e econômicos, as organizações beneficentes, as autoridades locais, a indústria e os meios de comunicação. As pessoas de todos os meios sociais estão implicadas tanto com os indivíduos quanto com as famílias e comunidades. Aos grupos sociais e profissionais e ao pessoal do grupo sanitário corresponde, especialmente, assumir a responsabilidade de atuar como mediadores entre interesses antagônicos e a favor da saúde.” (p. 2)

A ampliação do conceito de saúde, fundamental para a constituição de um campo de conhecimentos e práticas para a promoção, parte do reconhecimento da insuficiência do modelo biológico, da tecnologia médica e do foco exclusivo no risco individual para responder aos processos de saúde-doença.

Nesse sentido, convém ressaltar que a própria idéia de "processo" aborda a saúde e a doença numa relação dinâmica, na qual interagem elementos de agressão e defesa, tanto internos como externos ao organismo, em uma permanente instabilidade que desencadeia novos ajustes a todo instante. Portanto, além da saúde não se constituir numa ausência de doença, uma vez que ambas interagem constantemente e não é possível estar definitivamente saudável ou totalmente doente, também esta relação se dá para além das fronteiras internas do organismo, cujas relações sociais e o meio físico externo se somam às características imunogenéticas individuais (OPS, 1996; Carvalho e col, 1998; Buss, 2000).

Não é por acaso que a Carta de Ottawa, em 1986 (Brasil - MS, 2001,p. 2), ao defender a eqüidade sanitária, faz referência à promoção dos "meios que permitam a toda a população desenvolver ao máximo sua saúde potencial”.

Esse "máximo potencial" de saúde mencionado sugere um alinhamento conceitual da Carta à idéia de saúde-doença como processo, o que realiza um avanço em relação a um importante documento anterior, produzido em 1978, na Conferência Internacional so- bre Cuidados Primários de Saúde em Alma-Ata, que enfatiza a saúde como "estado de completo bem-estar físico, mental e social” (Brasil - MS, 2001: 15).

Mais do que um mero debate sobre o emprego de expressões, a diferença entre o "potencial" em Ottawa e o "completo" de Alma-Ata sugere importantes implicações conceituais que adquirem nitidez ao longo dos anos sem, contudo, perder de vista o ponto fundamental: a saúde envolve os demais setores da sociedade além do setor médico e dos demais profissionais da saúde. Aliás, como pondera Carvalho e col. (1998, p. 43) sobre a ampliação do conceito de saúde:

"Tal conceito, por um lado, sugere um certo avanço na síntese das concepções mais expressivas sobre saúde conhecidas na época. No entanto, revela-se contraditório por supor um "completo estado de bem-estar", o que por definição é impossivel de acontecer, uma vez que bem-estar físico, bem-estar mental e bem-estar social são estados de equilibrio instável, que se definem na medida do dinamismo e dos conflitos de sociedades concretas. Isto também exemplifica o caráter processual da saúde e da doença."

Convém ressaltar que o marco de referência da declaração de Alma-Ata parte dos cuidados primários de saúde e, nesta perspectiva, defende que estes envolvem, pelo menos, educação (no que tange aos principais problemas de saúde e aos métodos para sua prevenção e controle), além da distribuição de alimentos e nutrição apropriada; provisão adequada de água potável e saneamento básico; cuidados com a saúde materno-infantil; planejamento familiar; imunização; prevenção e controle de doenças endêmicas, bem como tratamento apropriado de lesões comuns e acesso a medicamentos essenciais. Entretanto, chama a atenção para a importância de se envolver nesses cuidados primários todos os setores e elementos correlatos ao desenvolvimento nacional e comunitário, tal como a agricultura, pecuária, produção de alimentos, indústria, educação, habitação, obras públicas e comunicações, entre outros, que ressaltam a importância dos demais setores sociais e econômicos. Ou seja (e eis um marco importante para as subseqüentes Conferências na área): a saúde não é de alçada exclusiva do setor sanitário (Brasil - MS, 2001).

Um interessante exemplo que converge com esse posicionamento ampliado da saúde é a contestação da ênfase na especialização da atenção médica que, 
além de demandar alto custo, perde em efetividade ao concentrar-se no tratamento de uma determinada doença num indivíduo, como se este estivesse isolado no tempo e no espaço. Aliás, como define Starfield ao tratar da atenção primária (2002,p. 20-1):

"A especialização direcionada ao tratamento da enfermidade não pode maximizar a saúde porque a prevenção da enfermidade e a promoção de um ótimo funcionamento transcendem as enfermidades específicas e requerem uma perspectiva mais ampla do que a que pode ser alcançada pelo especialista na enfermidade. A atenção médica eficaz não está limitada ao tratamento da enfermidade em si; deve considerar $o$ contexto no qual a doença ocorre e no qual o paciente vive. Além disso, raramente as enfermidades existem de forma isolada, especialmente quando apresentadas ao longo do tempo."

E, ainda tendo como referência a atenção primária, a autora complementa:

"Para que a atenção primária otimize a saúde, ela deve enfocar a saúde das pessoas na constelação dos outros determinantes de saúde, ou seja, no meio social e físico no qual as pessoas vivem e trabalham, em vez de enfocar apenas sua enfermidade individual" (Starfield, 2002,p. 27).

Nesse sentido, ter saúde é mais do que não estar doente, pois envolve uma concepção de vida com qualidade, a qual se traduz no cotidiano em bem-estar físico, mental e social $3 / 4$ se não completo, pelo menos, potencializado ao máximo. Para tanto, de fato, os prérequisitos da saúde e a maximização de seu potencial implicam necessariamente a participação de outros setores sociais e econômicos juntos ao setor sanitário. Porém, a participação conjunta desses setores, para ser sustentável, necessita vir acompanhada de justiça social e eqüidade, bem como paz, educação, moradia, alimentação, distribuição de renda e proteção do ecossistema, como defendeu em 1986 a Carta de Ottawa, ratificando importantes posições da AlmaAta (Brasil - MS, 2001).

Esta importante articulação aponta para a interdependência entre saúde e desenvolvimento e nos alerta que pouco adianta mobilizar setores sociais e sanitários se, conjuntamente, o crescimento econômico não beneficiar as condições de vida da população como um todo, questão abordada mais detalhadamente a seguir.

\section{Questões Sociais, Condições de Vida e Saúde}

Esta ênfase na compreensão da saúde como um processo, no qual se prioriza a vida com qualidade ao invés da ausência de doença, situa a promoção da saúde em oposição crítica à medicalização da vida social e em defesa do posicionamento político em torno de relações sociais mais eqüitativas. Esse ponto vem ao encontro, em especial, da diminuição da desigualdade do estado de saúde entre as populações de um mesmo país, e entre os países, como alerta a Declaração de Alma-Ata (Brasil - MS, 2001), assim como relaciona as condições de vida com os níveis de saúde da população.

Por sinal, a interação entre condições de vida e saúde foi largamente apontada ao longo da história. A própria tradição do modelo biomédico, baseado na doença e na medicalização da vida social, foi questionada já nos séculos XVIII e XIX nas origens da medicina social por sanitaristas como Villermé, Chadwick, Virchow, Neumann e Johann Peter Frank que identificavam, ao lado dos fatores físicos, fatores sociais e econômicos como causadores de epidemias (Buss, 200o; Minayo e col, 200o).

Assim, mesmo que de perspectivas e épocas diferentes, convergem nesta direção tanto os clássicos da saúde pública como a obra, de Johann Peter Frank, do século XVIII, "A miséria do povo, mãe das enfermidades" (Buss, 200o), como ratificam contemporaneamente estudos, cujo ponto principal pode ser resumido na seguinte correlação (Starfield, 2002,p. 26):

"Quanto mais recursos sociais de indivíduos e comunidades, maior a probabilidade de uma saúde melhor. Além disso, a privação social relativa, mais do que a absoluta, também está associada a uma saúde pior. Ou seja, quanto maiores as disparidades na riqueza em qualquer população, maior as disparidades na saúde."

1 No original: "Good health is the bedrock on which social progress is built. A nation of healthy people can do those things that make life worthwhile, and as the level of health increases so does the potential for happiness". 
Dessa forma, temos mais um importante ponto de convergência estabelecido no que tange à inter-relação entre as condições de vida e a saúde e as suas profundas correlações com o desenvolvimento social (Castellanos, 1998).

Interessante ressaltar que a medicina social, em especial a dos séculos XVIII e XIX, ao lidar com estas correlações traduz uma perspectiva predominantemente "utilitarista" da saúde, na qual a doença dos povos consiste num empecilho ao crescimento de um país. As condições de vida, portanto, deveriam ser protegidas para a manutenção da riqueza das nações, o que estabelece um limite para os níveis de pobreza da população, como uma "margem de risco" para doenças, uma vez que pessoas doentes não trabalham e, sem trabalho, não se produz e acumula capital (Buss, 2000; Minayo e col, 200o).

Contudo, as repercussões das condições de vida e saúde, bem como a sua decorrente implicação no crescimento econômico, ganha no século XX novos elementos. 0 emblemático prefácio do relatório Lalonde, em 1974 3/4 documento o qual, segundo Rootman e $\operatorname{col}(2000)$, teria organizado o campo da promoção da saúde3/4reafirma a correlação entre saúde e crescimento econômico: "boa saúde é a base na qual se ergue o progresso social" (Lalonde, 1974, p. 05). Porém, faz também a defesa de que pessoas saudáveis podem realizar coisas que fazem a vida valer a pena e, à medida que a saúde aumenta, igualmente se eleva o potencial para a felicidade. Desta forma, relaciona a busca da felicidade e da realização a um ganho potencializado pela saúde.

A perspectiva da felicidade dos indivíduos através da eqüidade é reforçada anos depois com a Declaração de Alma-Ata, na qual a saúde é apontada também como elemento fundamental, ao mesmo tempo, para a qualidade da vida e a paz entre as nações, como aponta o terceiro item da Declaração (Brasil - MS, 2001): "A promoção e proteção da saúde dos povos é essencial para o contínuo desenvolvimento econômico e social e contribui para a melhor qualidade de vida e para a paz mundial”.

Podemos considerar que, no curto período do Relatório Lalonde à Declaração de Alma-Ata, ganha consistência a retomada da associação entre a eqüidade em saúde e a melhoria de condições de vida como fatores indispensáveis para os indivíduos, bem como para os países e suas relações internacionais.
Assim, a saúde é abordada não só como fator de crescimento econômico mas de contribuição à paz entre as nações $3 / 4$ preocupação emergente no panorama do século XX, com a internacionalização das economias dos países centrais e mundialização da pobreza entre os periféricos.

Com tal reafirmação do vínculo de interdependência entre saúde e condições de vida é como se também retomássemos, pelo debate em conferências e fóruns internacionais da promoção da saúde, as preocupações com relações sociais mais eqüitativas; a concentração de renda e o aumento da pobreza não só dentro dos países, mas também em suas relações em um mundo que rumava à globalização numa perspectiva neoliberal.

\section{A Prevenção das Doenças e a Promo- ção da Saúde}

Outra importante característica da contemporânea discussão sobre a promoção da saúde reafirma a questão dos limites do modelo biomédico (discutida na primeira seção deste artigo) para enfatizar os cuidados com a saúde, ao invés de concentrar recursos e ações na assistência e cura de enfermidades. Tal prioridade tem fortes raízes na medicina comunitária que, também reconhecendo a correlação entre condições de vida e saúde, procurou em meados do século XX, orientar a saúde pública na perspectiva da prevenção, sustentando o modelo da história natural da doença. Esse ponto é detalhado por Carvalho e col (1998: 52), quando menciona que:

"Tal modelo é desenvolvido nos Estados Unidos, no âmbito das práticas da medicina comunitária, uma estratégia de contenção de pobreza dentro do contexto de crise do capitalismo e de incremento da emigração dos países do terceiro mundo. É também conhecido como "Modelo de Leavell \& Clark", em homenagem aos dois médicos sanitaristas norte-americanos que o propuseram na década de 5o."

Neste modelo, a promoção da saúde também está contemplada. Entretanto sua conformação se dá no âmbito de um paradigma de história natural da doença, cuja ênfase se concentra na prevenção das doenças, procurando se antecipar e evitar que elas ocorram, a partir de ações que visam (re)estabelecer o equi- 
líbrio dinâmico entre o hospedeiro, o agente patogênico e o meio. Necessariamente, tal noção preventiva envolve a epidemiologia na tentativa de controle da transmissão de doenças infecciosas e na redução dos riscos para doenças crônico-degenerativas (Czeresnia, 2003). Entendidos numa relação de causa-efeito, a abordagem dos três elementos situa a prática médica em duas fases: uma, pré-patogênica, na qual os elementos ainda se encontram em equilíbrio e, outra, designada como patogênica, devido à manifestação de uma doença originada no decorrente desequilíbrio entre os citados elementos (Buss, 200o).

Nesse modelo, a promoção da saúde foi localizada no primeiro de três níveis de prevenção (o da prevenção primária) e lá responderia pelas ações da fase prépatogênica, de modo a zelar, através de ações de proteção específica contra os agravos, com prevenção e educação em saúde. Dessa forma, segundo o clássico modelo de Leavell \& Clark, a prevenção primária zelaria pela manutenção do equilíbrio entre hospedeiro, agente patogênico e meio ambiente.

Por sua vez, a atenção primária também converge nesta defesa de serviços de teor preventivo, como ilustra Starfield (2002, p. 29):

"A atenção primária difere da atenção por consulta, de curta duração (atenção secundária) e do manejo da enfermidade a longo prazo (atenção terciária) por várias características. A atenção primária lida com problemas mais comuns e menos definidos, geralmente em unidades comunitárias como consultórios, centros de saúde, escolas e lares. Os pacientes têm acesso direto a uma fonte adequada de atenção que é continuada ao longo do tempo, para diversos problemas e que inclui a necessidade de serviços preventivos."

Contudo, uma contemporânea definição de promoção da saúde a identifica como uma estratégia (ou conjunto de estratégias) que envolve um campo de conhecimentos e práticas transversais a todas as ações e níveis de atenção em saúde. Não se constitui em um nível específico de atenção e, tampouco, se situa em ações anteriores à prevenção, como se encontra bem caracterizada literalmente no tocante a esse ponto, no documento, por uma política nacional de promoção da saúde (Brasil - MS, 2002,p. 14):

"Deve ficar claro que a promoção da saúde não deve ser mais um nivel de atenção, nem deve corresponder a ações que acontecem anteriormente à pre- venção. Com esta compreensão não deve se constituir como mais um programa, mais uma estrutura organizacional. Ao contrário, se compõe de estratégias que se movem transversalmente em todas as políticas, programas e ações do setor saúde, numa integralidade em toda a sua complexidade e singularidade social e individual."

Esta dimensão transversalmente intersetorial, sem que se perca de vista o reconhecimento da importância da atenção primária, defendida em Alma-Ata e ratificada em Ottawa, aproxima a promoção da saúde mais da questão da qualidade de vida do que do controle das enfermidades.

Por sinal, reside nesse ponto a significativa diferença entre a prevenção das doenças, orientada por um modelo baseado na história natural da doença, e a promoção da saúde entendida, retomando argumento já referido anteriormente, como vida com qualidade e não apenas ausência de enfermidades. Esta abordagem, por sua vez, inscreve a promoção da saúde mais coerentemente no modelo dos determinantes sociais da saúde, do que comporta a noção de processo saúde-doença como histórica e socialmente marcados.

Esta ampliação da saúde opera a sua abordagem por um conceito "positivo", ou seja, que busca a definição da saúde por sua ampla ramificação e presença cotidiana e não por sua ausência, como no caso de uma enfermidade. Entretanto, a noção de que saúde seja vida com qualidade, ao mesmo tempo que coloca a questão dos determinantes sociais, amplia o campo semântico e favorece imprecisões. Aliás, sobre esse problema, pondera Minayo e col (2000,p. 8):

"Tornou-se lugar comum, no âmbito do setor saúde, repetir, com algumas variantes, a seguinte frase: "saúde não é [ausência de] doença, saúde é qualidade de vida". Por mais correta que esteja, tal afirmativa costuma ser vazia de significado e, freqüentemente, revela a dificuldade que temos como profissionais da área, de encontrar algum sentido teórico e epistemológico fora do marco referencial do sistema médico que, sem dúvida, domina a reflexão e a prática do campo da saúde pública. Dizer, portanto, que o conceito de saúde tem relações ou deve estar mais próximo da noção de qualidade de vida, que saúde não é mera ausência de doença, já é um bom começo, porque manifesta o mal-estar com o reducionismo médico. Porém, pouco acrescenta à reflexão." 
De fato, se situamos o conceito de saúde num modelo diferente do da história natural da doença e procuramos a sua positividade, devemos empreender esforços para que nossa abordagem sobre qualidade de vida possa verdadeiramente contemplar questões como a busca da felicidade, realização de potenciais pessoais e coletivos, vida que valha a pena ser vivida, entre outras questões não resolvidas exclusivamente pela lógica da prevenção.

Provavelmente, tal movimento necessitará de conhecimentos de outras áreas do conhecimento científico, bem das artes e filosofias, saberes populares e práticas religiosas ainda pouco legitimadas, para falar de saúde. Mas, certamente, como aponta Czeresnia (2003), não será apenas com a perspectiva da prevenção e da racionalidade médica que poderemos dar conta do problema da complexidade (e oportunidade) que a noção de qualidade de vida nos oferece na perspectiva da promoção da saúde.

Por outro lado, no contexto brasileiro, no qual os serviços de saúde enfrentam dificuldades básicas de provisão (atendimento médico, exames, equipamentos, materiais, medicamentos, entre outros), a preocupação com a qualidade de vida e a busca da felicidade pode parecer despropositada, ou comprometida com a retração de investimentos em políticas públicas. Este consiste num importante desafio a ser enfrentado na discussão sobre qualidade de vida no âmbito da saúde pública: que esta não ocorra em prejuízo da atenção e provisão de serviços e políticas de saúde, em todos os níveis de atenção.

Por sua vez, tal concentração de relevância na "qualidade de vida" e nos hábitos e estilos de vida saudáveis pode contribuir para que a promoção da saúde seja reduzida a um conjunto normativo de novos consumos em saúde, como criticamente nos lembra Nogueira a respeito da higiomania e da somatolatria (2001, p. 65):

"A higiomania e a somatolatria constituem a orientação predominante numa enorme quantidade de revistas, livros e sites da internet dedicados ao assunto. De sua parte, a nova saúde pública e os organismos internacionais da área procuram difundir a filosofia de promoção da saúde, que tem propósito muito similar à adoção dos chamados hábitos ou estilos de vida saudáveis. Podemos perguntar, então, em que aspectos ou orientações, a promoção da saúde distin- gue-se da voga da higiomania, ou seja, se ela tem, acerca da saúde, uma visão diferente."

De fato, se nossa perspectiva com a promoção da saúde é a de focar apenas a responsabilidade individual para com estilos de vida saudáveis haverá pouca diferença com a higiomania e a somatolatria. Por outro lado, se nos recusamos a ter que escolher entre reducionismos, ou seja, abordar a saúde pelo viés do reducionismo médico ou de um "reducionismo individualista”, podemos vislumbrar uma potencial interação entre conhecimentos e práticas de setores médicos e populares. Assim, temos diante de nós a possibilidade de não polarizar a discussão em medicina versus sociedade e, tampouco, sociedade versus indivíduo, o que favorece a (re)orientação do emprego da promoção da saúde para a adequação de políticas, programas e serviços, como forma de enfrentar tanto a medicalização da vida social como a individualização da saúde pública.

Dessa forma, somos levados a considerar que, no enfrentamento desses desafios que a promoção da saúde recoloca à saúde pública, a participação social desempenha um papel de grande importância, como discutido a seguir.

\section{Considerações Finais: Perspectivas da Participação Social na Promoção da Saúde}

O início do século XXI nos traz o legado do final do século anterior que nos faz padecer da falta de práticas utópicas, estas entendidas aqui no sentido defendido por Paulo Freire (1985,p. 10o) quando nos alerta:

"Mas não utópica no sentido do irrealizável; não utópica no sentido de quem discursa sobre o impossivel, sobre os sonhos impossíveis. Utópica no sentido de que é esta uma prática que vive a unidade dialética, dinâmica, entre a denúncia e o anúncio do sonho possivel."

Talvez, após percorrer alguns de seus referenciais, não seja exagero postular que a promoção da saúde possa se somar a novas utopias para este século que se inicia. Uma utopia marcada pelos sonhos possíveis quando retoma e aprofunda as promessas da reforma sanitária brasileira e as boas práticas no Sistema Único de Saúde, bem como a renovação de nossas preocu- 
pações com a justiça social e a eqüidade em saúde. Esses assuntos, na saúde pública, como em outras questões sociais, andaram recobertos pela descrença, tratados com caricatura panfletária ou ingenuidade ativista, mas que, de forma contundente, insistem em emergir, plenos de sua dimensão histórica e repletos de novas paixões pelo conhecer e agir, agir e transformar.

A "saúde para todos no ano 200o", como postulou a Declaração de Alma-Ata e ratificaram as Cartas das conferências internacionais, não veio, e assistimos ainda, com o avanço do modelo neoliberal de globalização, propostas de promoção da saúde correrem o risco de legitimarem ideologicamente a retração das políticas sociais do Estado, bem como a culpabilização da população diante da falta de autocuidado. Estas ponderações, muitas delas feitas na própria saúde pública, por um lado, favoreceram a manutenção do espírito crítico sobre a promoção mas, por outro, também possibilita leituras distorcidas e preconceituosas sobre a importância da qualidade de vida, do fortalecimento das habilidades pessoais e do reforço da ação comunitária como se estivessem sempre desvinculadas do modelo dos determinantes sociais da saúde.

Contudo, vieram os grupos de reflexão, ação e estudo; os encontros nacionais e internacionais; as orientações de alternativas possíveis; as alianças entre os serviços de saúde e a população organizada; a clarificação e o aperfeiçoamento dos conceitos, bem como sua adequação aos contextos nacionais. Vieram todos aqueles que colaboram com a produção de um novo enfoque sobre antigas questões da saúde pública, inovando na promoção da saúde com a ênfase em um campo de práticas e de reorientação de serviços, com marcos legais e legislação específicos, políticas públicas saudáveis e intersetoriais e a ampliação das ações com novos protagonistas e atores sociais na área da saúde.

Provavelmente o que fará a diferença para a promoção da saúde entre ser instrumento do neoliberalismo ou da igualdade social, de fato, seja a participação social. Com ela é que poderemos enfrentar a polissemia da "qualidade de vida", a fim de movê-la da retórica vazia que atende a interesses privados na saúde em detrimento de interesses públicos e, em especial, dos das classes populares, bem como defender que a participação social com reforço da ação comunitária e estímulo à autonomia dos indivíduos não se desdobrem em culpabilização da população, mas sim, numa opor- tunidade coerente para a quebra da exclusividade do "setor sanitário" e empresarial sobre a saúde pública.

Importante ressaltar que a participação social encontra dispositivos que a regulamentam no próprio Sistema Único de Saúde (SUS), principalmente no que se refere aos processos decisórios e ao controle social, como dispostos na Lei No 8.142 de 28 de dezembro de 1990. Na perspectiva da promoção da saúde, a participação social também está colocada em bases de mobilização; entretanto, a ênfase está na atuação e co-responsabilização, onde a capacitação e o desenvolvimento de estratégias de ação visam articular a população para maior controle sobre sua saúde e suas condições de vida, tanto no campo individual como no coletivo $3 / 4$ sem que isto ocorra em detrimento da assistência de qualidade por parte das políticas e serviços de saúde.

Não se trata, portanto, de concentrar os espaços de participação na fiscalização e controle social sobre as políticas, mas, sobretudo, de concebê-lo, também, como um potencial para ações conjuntas com os próprios serviços de saúde que implicam tanto a aproximação entre população e serviços, bem como a mobilização e atuação social na saúde. Como ilustração deste ponto, sustenta a proposta da política nacional de promoção da saúde (Brasil, 2002,p. 19) quando caracteriza de modo amplo a participação:

“A participação da população não somente nas instâncias formais, mas em outros aspectos constituídos por atividades sistemáticas e permanentes, dentro dos próprios serviços de atendimento, favorecendo a criação de vínculos entre o serviço e os usuários, caracterizando uma participação mais criativa e realizadora para as pessoas."

Contudo, claro está que esses marcos legais, como também a perspectiva da promoção da saúde, apesar de fundamentais, não asseguram, por si, a sua concretização, nem tampouco a autenticidade da participação social em termos de autonomia, expressão e defesa de seus interesses. Assim, a participação, apesar de se beneficiar do reconhecimento formal e legal, só se efetivará se puder ocupar de modo sistemático e sustentável esses e outros espaços que, por sinal, só foram abertos como resultado da própria mobilização e atuação da população.

A discussão alinhavada neste artigo com contornos históricos, referenciais, documentos e marcos le- 
gais nos sugere que, em especial para a América Latina, a participação social na saúde poderá desempenhar um importante papel na adequação da promoção da saúde à luta pela saúde pública e de qualidade.

\section{Referências}

BRASIL. Ministério da Saúde. Promoção da saúde, Declaração de Alma-Ata, Carta de Ottawa, Declaração de Adelaide, Declaração de Sundsvall, Declaração de Santafé de Bogotá, Declaração de Jacarta, Rede dos Megapaíses, Declaração do México. Brasília, DF, 2001. 54 p.

BRASIL. Ministério da Saúde. Secretaria de Políticas de Saúde. Política Nacional de Promoção da Saúde: documento para discussão. Brasília, DF, 2002. 41 p.

BUSS, P. M. (Ed). Promoción de la saludy la salud pública: una contribuición para el debate entre las escuelas de salud pública de América Latina y el Caribe. Rio de Janeiro: Mimeo, 200o. 203 p.

CARVALHO, A. I. et al. (Org.). Gestão de saúde: curso de aperfeiçoamento para dirigentes municipais de saúde. Rio de Janeiro: FIOCRUZ; Brasília: UnB, 1998. 57 p.

CASTELLANOS, P. L. Los modelos explicativos del processo salud-enfermidad: los determinantes sociales. In: MARTINEZ NAVARRO, F. et al. Salud Publica. Madrid: Mcgraw-Hill-Interamericana, 1998. p. 81-102.

CZERESNIA, D. O conceito de saúde e a diferença entre prevenção e promoção. In: CZERESNIA, D.; FREITAS, C. M. (Org.). Promoção da saúde: conceitos, reflexões, tendências. Rio de Janeiro: Editora Fiocruz, 2003. p. 39-53.
FREIRE, P. Educação: o sonho possível. In: Brandão, C. R. (Org.). O educador: vida e morte. Rio de Janeiro: Graal, 1985. p. 89-101.

LALONDE, M. A new perspective on the health of Canadians. 1974. Disponível em: <http://www.hcsc.gc.ca/hppb/phdd/pdf/perspective.pdf > Acesso em: 17 jan. 2003 .

MINAYO, M. S.; HARTZ, Z. M. A.; BUSS, P. M. Qualidade de vida e saúde: um debate necessário. Ciência \& Saúde Coletiva, Rio de Janeiro, v.5, n.1, p. 7-18, mar. 2000 .

NOGUEIRA, R. P. Higiomania: a obsessão com a saúde na sociedade contemporânea. In: VASCONCELOS, E. M.(Org.). A saúde nas palavras e nos gestos. São Paulo: Hucitec, 2001. p. 63-72.

ORGANIZAÇÃO PANAMERICANA DA SAÚDE (OPS). Promoción de la salud: una antología. Washington, 1996. 364 p. (Publ. Cient. 557).

ROOTMAN, I.; POLAND, B. D.; GREEN, L. W. The settings aproach to health promotion. In: ROOTMAN, I. et al. (Ed.). Settings for health promotion: linking theory and pratice. London: Sage Publications, 2000. 384 p.

STARFIELD, B. Atenção primária: equilibrio entre necessidades de saúde, serviços e tecnologia. Brasília: UNESCO, Ministério da Saúde, 2002. 726 p. 